Article

\title{
Amorphous Silicon Carbide Platform for Next Generation Penetrating Neural Interface Designs
}

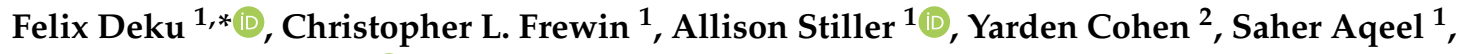 \\ Alexandra Joshi-Imre ${ }^{1}\left(\mathbb{D}\right.$, Bryan Black ${ }^{1}$, Timothy J. Gardner ${ }^{2}$, Joseph J. Pancrazio ${ }^{1}$ and \\ Stuart F. Cogan ${ }^{1}$ \\ 1 Department of Bioengineering, University of Texas at Dallas, Richardson, TX 75080, USA; \\ christopher.frewin@utdallas.edu (C.L.F.); axs169031@utdallas.edu (A.S.); saher.aqeel@utdallas.edu (S.A.); \\ alexandra.joshi-imre@utdallas.edu (A.J.-I.); bjb140530@utdallas.edu (B.B.); \\ joseph.pancrazio@utdallas.edu (J.J.P.); stuart.cogan@utdallas.edu (S.F.C.) \\ 2 Department of Biology and Biomedical Engineering, Boston University, Boston, MA 02215, USA; \\ yardenc@bu.edu (Y.C.); timothyg@bu.edu (T.J.G.) \\ * Correspondence: felix.deku@utdallas.edu; Tel.: +1-469-667-0634
}

Received: 31 July 2018; Accepted: 17 September 2018; Published: 20 September 2018

\begin{abstract}
Microelectrode arrays that consistently and reliably record and stimulate neural activity under conditions of chronic implantation have so far eluded the neural interface community due to failures attributed to both biotic and abiotic mechanisms. Arrays with transverse dimensions of $10 \mu \mathrm{m}$ or below are thought to minimize the inflammatory response; however, the reduction of implant thickness also decreases buckling thresholds for materials with low Young's modulus. While these issues have been overcome using stiffer, thicker materials as transport shuttles during implantation, the acute damage from the use of shuttles may generate many other biotic complications. Amorphous silicon carbide (a-SiC) provides excellent electrical insulation and a large Young's modulus, allowing the fabrication of ultrasmall arrays with increased resistance to buckling. Prototype a-SiC intracortical implants were fabricated containing 8 - 16 single shanks which had critical thicknesses of either $4 \mu \mathrm{m}$ or $6 \mu \mathrm{m}$. The $6 \mu \mathrm{m}$ thick a-SiC shanks could penetrate rat cortex without an insertion aid. Single unit recordings from SIROF-coated arrays implanted without any structural support are presented. This work demonstrates that a-SiC can provide an excellent mechanical platform for devices that penetrate cortical tissue while maintaining a critical thickness less than $10 \mu \mathrm{m}$.
\end{abstract}

Keywords: amorphous silicon carbide; neural stimulation and recording; insertion force; microelectrodes; neural interfaces

\section{Introduction}

Penetrating microelectrode arrays (MEAs) that stimulate or record neural activity usually consist of a base substrate material which may be an insulator or conductor. Typical conducting substrates include silicon [1], tungsten, iridium wire [2,3], and carbon fiber [4-7], which provide the backbone and structural stiffness necessary to penetrate neural tissue. For the Utah array, silicon is doped to provide conductivity [8], and is usually insulated so that current conduction is restricted to the doped silicon. A common polymeric coating used to isolate the conducting substrate from the surrounding electrolyte is Parylene C. It is also common practice to use thin-film dielectric materials, such as low pressure chemical vapor deposited (LPCVD) $\mathrm{SiO}_{2}$, to encapsulate polycrystalline silicon traces [9]. In most cases another dielectric material, such as $\mathrm{Si}_{3} \mathrm{~N}_{4}$, is deposited over the $\mathrm{SiO}_{2}$ to control the intrinsic compressive stress in the $\mathrm{SiO}_{2}[10,11]$ or to create a multilayer passivation stack of $\mathrm{PECVD} \mathrm{SiO}_{2} / \mathrm{Si}_{3} \mathrm{~N}_{4} / \mathrm{SiO}_{2}$ over 
the conducting trace [12]. The silicon - based microelectrodes, however, have been shown to deteriorate when chronically implanted [13-15]. Failure modes associated with silicon - based MEA degradation were recently described following array implantation in non-human primates [14].

Recent studies have shown that flexible neural interfaces may provide an alternative to traditional silicon-based implants and have the potential to greatly improve the chronic longevity of the implanted microelectrodes [2,16]. Polymers such as polyimide [17,18], Parylene-C [19,20], SU-8 [21], polydimethylsiloxane (PDMS) [22], and shape memory polymers [23,24] have been investigated as substrates for neural stimulation and recording microelectrodes. Their low Young's modulus reduces the mechanical mismatch between neural tissue and the implanted device. Thin-film metal conducting traces such as gold or platinum are used between layers of the polymer substrate connecting electrode sites and bond pads. The insulating layers effectively sandwich the conducting traces. Electrode sites are then created by removing or etching the top layer through a precise and controlled microfabrication process.

Implantation of some penetrating polymer-based MEAs have been aided by a delivery vehicle [5,25-28] or temporary support structure [5,29-31] to minimize buckling during insertion by increasing the critical buckling load [32]. To penetrate neural tissue without the assistance of support structures, a minimum cross-sectional dimension of the shank (the part that penetrates the neural tissue) is typically greater than $20 \mu \mathrm{m}[18,21,33]$. Unfortunately, this cross-sectional dimension may still be higher than that required to ameliorate the foreign body reaction, noting that the prevailing thought has been that the minimum geometric dimension requirement, at least in one dimension, should be under $10 \mu \mathrm{m}$ [34]. We recently described the development of multielectrode arrays based on PECVD amorphous silicon carbide (a-SiC) [35]. Amorphous $\mathrm{SiC}$ was chosen because it exhibits robust chemical inertness [36], high electronic and ionic resistivity [37], biocompatibility [37-40], and is amenable to thin-film fabrication processes [35]. Crystalline SiC has also been used as a material in the fabrication of MEAs and, because it is a wide bandgap semiconductor that can be doped for electronic conductivity, it may be used for conductive traces or as a low-impedance electrode, as well as an insulator [41-45]. The 16 channel MEAs were developed with two a-SiC layers sandwiching a thin-film $\mathrm{Au}$ conducting trace. Each shank was $10 \mu \mathrm{m}$ wide and $2 \mathrm{~mm}$ long and had a shank cross-sectional area below $45 \mu \mathrm{m}^{2}$. The greatly reduced shank cross-sectional dimensions may promote compliance with neural tissue when implanted [46]. The electrode sites were opened at the distal tips by removing the top a-SiC layer and were coated with sputtered iridium oxide films (SIROF) or titanium nitride (TiN) to reduce electrode impedance [35].

Here, we evaluate different approaches of reducing the critical buckling load of a-SiC MEAs having individual shank cross-sectional area below $45 \mu \mathrm{m}^{2}$, and demonstrate insertion of multiple a-SiC MEA shanks into rat cortex. Acute extracellular neural recording from the a-SiC MEAs following array insertion is also presented.

\section{Materials and Methods}

\subsection{Thin Film Deposition and Array Fabrication}

Plasma enhanced chemical vapor deposited a-SiC films using the Plasmatherm Unaxis 790 series deposition system are used as substrates for MEA development. The a-SiC films are deposited at $1000 \mathrm{mTorr}, 350{ }^{\circ} \mathrm{C}$, and $0.27 \mathrm{~W} / \mathrm{cm}^{2}$ using a $\mathrm{SiH}_{4}: \mathrm{CH}_{4}$ gas ratio of 1:3. A $2 \mu \mathrm{m}$ or $4 \mu \mathrm{m}$ thick a-SiC film forms the bottom layer of the MEA. The bottom a-SiC layer is followed by the deposition of approximately $350 \mathrm{~nm}$ thick patterned gold layer that forms the interconnecting traces. A thin $(<50 \mathrm{~nm})$ film of titanium is deposited as an adhesion layer between the a-SiC and gold on both surfaces of the metal to form a trilayer metal structure of $\mathrm{Ti} / \mathrm{Au} / \mathrm{Ti}$. A second $2 \mu \mathrm{m}$ a-SiC layer was deposited over the metal traces and bottom a-SiC layer to produce either a $4 \mu \mathrm{m}$ or $6 \mu \mathrm{m}$ thick a-SiC superstructure. The details of the fabrication have been reported previously [35]. Briefly, a $1 \mu \mathrm{m}$ polyimide (HD Microsystems PI 2610) release layer is spin-coated on to a $100 \mathrm{~mm}$ silicon wafer and cured at $350{ }^{\circ} \mathrm{C}$ 
under $\mathrm{N}_{2}$ for $1 \mathrm{~h}$. The bottom a-SiC layer is deposited on the polyimide followed by a bilayer photolithography process, using LOR5A (Microchem Inc., Westborough, MA, USA) and Shipley S1813 (Microposit, Marlborough, MA, USA) photoresists, to define the metallization pattern. The metal was sputtered or evaporated, and the sample soaked in EBR-PG (Microchem Inc. Westborough, MA, USA) to complete the lift-off process. The second a-SiC layer was then deposited over the metallization and the bottom a-SiC the complete the thin-film stack. The $350{ }^{\circ} \mathrm{C}$ deposition temperature of the second a-SiC results in an increase in tensile stress of the metallization by about $400 \mathrm{MPa}$, for either the evaporated or sputtered trilayers. For the overall device, the effect of the increase in metal tensile stress is a reduction in the overall device stress from about $100 \mathrm{MPa}$ compressive to near-neutral $(<20 \mathrm{MPa}$ compressive), recognizing that the overall stress in the device is dependent on the thickness and processing of the individual layers. Another photolithography process, using a positive photoresist, was used to define the electrode sites, bond pads and shape of the individual devices on the wafer. The devices were then formed by reactive ion etching of the exposed a-SiC in $\mathrm{SF}_{6}$ plasma using an inductively coupled plasma (ICP) etcher. After the etching process, the remaining resist was stripped and the wafer with the a-SiC MEAs are soaked in deionized water until the arrays release. An example of a 16-channel MEA fabricated by the process described is shown in Figure 1. The device is intended for intracortical studies with only the 2-mm long distal shanks penetrating the cortex. Photolithographic patterning provides a means of creating a variety of array geometries including straight and curved shanks (Figure 2).

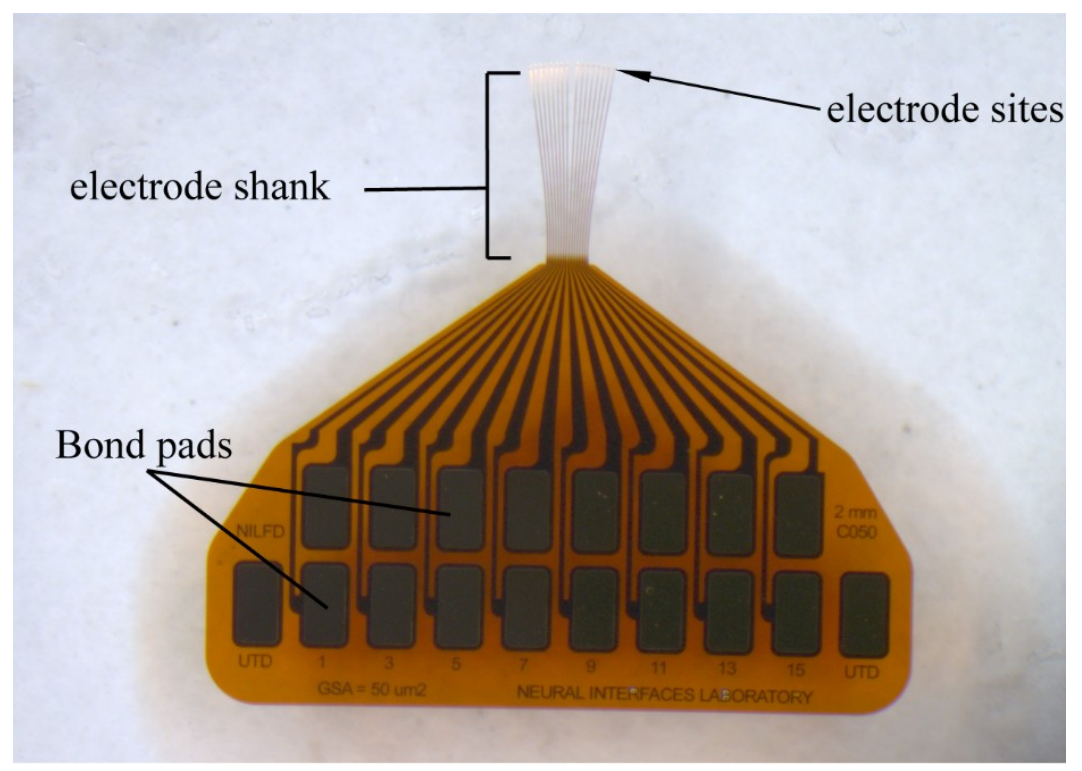

Figure 1. Example of the 16-channel a-SiC microelectrode array (MEA) showing bond pads at the proximal end, $2 \mathrm{~mm}$ long electrode shanks, and electrode sites located at the distal tips.

\subsection{Buckling and Insertion Mechanics}

Force measurements were made using a $20 \mathrm{~g}$ S-Beam load cell (Futek Advanced Sensor Technology, Inc., Irvine, CA, USA) mounted to a pneumatically controlled micro-positioner (Model 2650 Micropositioner, Kopf Instruments, Tujunga, CA, USA) which has predefined speed settings ranging from $1 \mu / \mathrm{s}$ to $4 \mathrm{~mm} / \mathrm{s}$. The micromanipulator is hydraulically driven and thus the motion is continuous. The steps in the forcetime curves are due to the sampling frequency of the recording equipment used to measure the load cell output. The sample probe was mounted on a screw which was directly threaded into the bottom of the load cell so that compression forces could be measured as the MEA was inserted into the brain tissue. Before implantation, the probe was lowered until it was directly above the surface of the brain. The load cell was then tared, and the probe inserted $2 \mathrm{~mm}$ into the brain at a constant rate of $50 \mu \mathrm{m} / \mathrm{s}$. For the measurements of buckling forces on glass substrates, 
the load cell was tared with a slight compressive stress on the tip and then retracted from the surface. This procedure results in an initial tensile deflection in the force-time curve immediately prior to the probe tip striking the glass surface.

\subsection{Surgery and a-SiC Implantation}

All surgical procedures were performed under the approval of the University of Texas at Dallas Institutional Animal Care and Use Committee (IACUC). Long Evans rats were deeply anaesthetized with $5 \%$ isoflurane vapor and administered an intraperitoneal KXA cohort consisting of ketamine $(65 \mathrm{mg} / \mathrm{kg})$, xylazine $(13.33 \mathrm{mg} / \mathrm{kg})$, and acepromazine $(1.5 \mathrm{mg} / \mathrm{kg})$ cocktail. The anesthesia was maintained at 0.5 to $1.5 \%$ throughout the remainder of the procedure. A 1 to $2 \mathrm{~mm}$ square craniotomy was centered $2.5 \mathrm{~mm}$ rostral and $2.5 \mathrm{~mm}$ lateral to bregma, and bone debris was carefully removed using sterile phosphate buffered solution (PBS). The dura was reflected using a dura pick and the surface of the brain was kept moist with sterile PBS. The Omnetics 18 pin male connector attached to the a-SiC cortical implant was placed within a NeuroNexus IST implantation tool (NeuroNexus, Ann Arbor, MI, USA) and loaded onto a Kopf Model 2650 hydraulic micropositioner (David Kopf Instruments, Tujunga, CA, USA). The implant was inserted to a depth of 1.5 to $2 \mathrm{~mm}$ from the cortical surface at an insertion rate of $50 \mu \mathrm{m} / \mathrm{s}$ at a location at the center of the craniotomy, deviating only enough to avoid large surface vasculature. The dura was sealed using Kwik Cast silicone elastomer (World Precision Instruments, Saratosa, FL, USA), followed by a layer of GLUture Octyl/Butyl cyanoacrylate glue (World Precision Instruments, Sarasota, FL, USA). A protective head cap was constructed using two-part dental cement (Stoelting Co., Wood Dale IL, USA) which served to secure and support the implant as well as protect the surgical site. The scalp wound was sutured, and the animal was administered an intramuscular injection of Cefazolin $(5 \mathrm{mg} / \mathrm{Kg})$, a subcutaneous injection of sustained release Buprenorphine $(0.15 \mathrm{mg} / \mathrm{Kg})$, and $2 \mathrm{~mL}$ of $0.9 \%$ saline. The rat was individually housed following implantation. Clavamox was administered orally and buprenorphine was administered every $72 \mathrm{~h}$ for one week.

\subsection{In Vivo Recording and Analysis}

Following construction and curing of the surgical head cap, recordings for a period of $10 \mathrm{~min}$ were collected using an OmniPlex Neural Acquisition System (Plexon Inc., Dallas, TX, USA) connected to the a-SiC array via Omnetics connector and a 16-channel digital headstage. Wideband signals $(0.1-7000 \mathrm{~Hz})$ were recorded simultaneously from all 16 electrodes at $40 \mathrm{kHz}$ sampling frequency and later filtered offline using a 4-pole Butterworth high pass filter $(250 \mathrm{~Hz})$. A $-4 \sigma$ threshold based on RMS noise calculations was applied to filtered continuous data to identify potential waveforms (or spikes). Single units were identified manually based on 2D principal component clustering using Plexon's Offline Sorter software (Plexon, Dallas, TX, USA). Sorted units which were not comprised of at least 100 individual spikes or which exhibited greater than $0.5 \%$ spike refractory period violations were excluded from analysis. Signal-to-noise ratios (SNR) were calculated by dividing the mean peak-to-peak amplitude of each unit by the adjusted RMS noise of the associated channel, which excluded values greater or less than $\pm 4 \sigma$ of the filtered continuous signal.

\section{Results and Discussions}

The 16-channel a-SiC MEAs were generally designed to mate with the 16-channel Omnetics connectors (A79040-001, Omnetics, Minneapolis, MN, USA). Gold bonding pads located at the proximal end of the MEA superstructure, $750 \times 500 \mu \mathrm{m}$ dimensions and pitch of $635 \mu \mathrm{m}$ ensured that the $16 \mathrm{a}-\mathrm{SiC}$ channels mated well with the connector. A solder reflow process using an indium-tin eutectic solder paste consisting of $52 \%$ In to $48 \%$ Sn (IND.1E, Indium Corporation, Clinton, NY, USA) was used to bond the pads on the connector to the gold bond pads on the MEA.

To characterize the functionality of the a-SiC platform, MEAs consisting of 16 penetrating shanks with one electrode per shank were fabricated (Figure 1). Each shank was 4 or $6 \mu \mathrm{m}$ thick, 2-4 mm 
long, and 7-10 $\mu \mathrm{m}$ wide with $25 \mu \mathrm{m}$ intershank separation. The shanks were designed with a straight outline and with 'arrow head' tip geometry. The shanks are sometimes intrinsically curved with the expectation that such geometry will direct the deployment of the shanks to a larger volume of brain tissue when implanted.

Figure 2 shows shank arrangements of the as-fabricated 16 channel a-SiC penetrating MEAs with (a) straight shanks of identical length and (b) intrinsically curve shanks. Tip profiles are shown in (c). Metal traces are $2 \mu \mathrm{m}$ wide and run centrally along the length of the shank. The electrode sites are located at the distal tip and are constrained in size and shape by the width of the shanks, such that the $50 \mu \mathrm{m}^{2}$ electrode sites were $2 \mu \mathrm{m}$ wide and $25 \mu \mathrm{m}$ long.

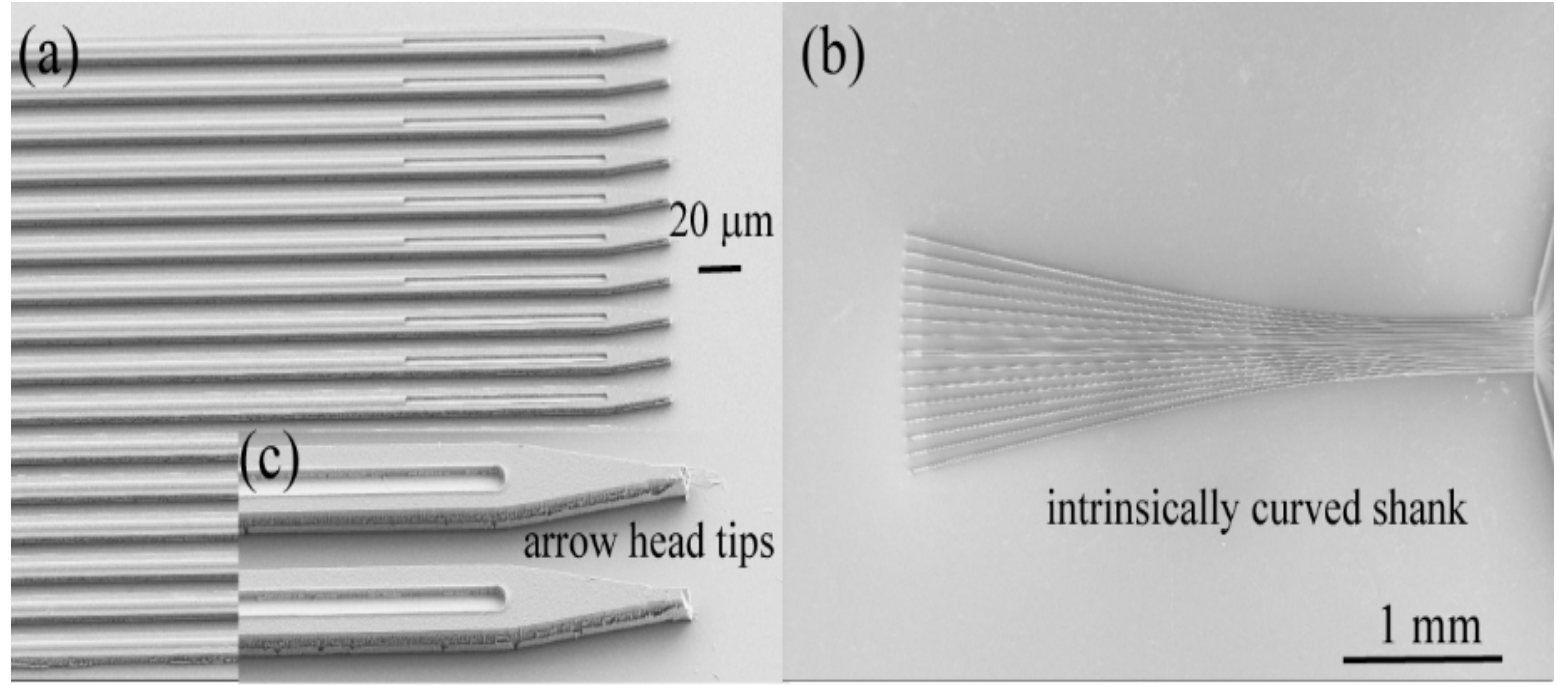

Figure 2. Scanning electron micrographs of as-fabricated 16 channel a-SiC intracortical ultramicroelectrode arrays with straight shanks of identical length (a) or intrinsically curve shanks (b). Tip profile and electrode site opening are shown in (c).

\subsection{Insertion of Ultrathin Shanks into Cortex}

\subsubsection{PEG-Stabilized Shanks}

While shanks with very small cross-sectional area offer the promise of reduced FBR, insertion of individual shanks into the neural tissue is challenging. Coating the shanks with polyethylene glycol (PEG) that temporarily stiffens the shanks while leaving a small portion of the tips exposed [5] is an approach previously shown to successfully aid insertion. The PEG coating increases the buckling threshold of the shanks and allows the arrays to be implanted. Using this method, we have inserted $4 \mu \mathrm{m}$ thick versions of the a-SiC arrays into rat brain.

An example of an array coated with PEG (MW 2000, Alfa Aesar, Tewksbury, MA, USA) prior to implantation is shown in Figure 3. Prior to PEG coating, the assembled a-SC array is placed on a mineral oiled aluminum surface. A single flake of PEG is placed on the proximal end of the separated shanks. The PEG is then melted onto the shanks with a soldering gun. As shown in Figure 3, the PEG coating was only used to strengthen the shanks towards the base of the MEA leaving the tips free to individually penetrate the brain. An insertion rate of $50 \mu \mathrm{m} / \mathrm{s}$ was used to insert the shanks so that, as the array is slowly advanced into the brain, the PEG coating dissolves on the surface of the brain without itself penetrating the tissue, preserving the sub $10-\mu \mathrm{m}$ dimensions of the shanks that are inserted into the brain. Based on visual observation with a surgical microscope, the shanks appear to penetrate the parenchyma of the brain without dimpling the cortex. 


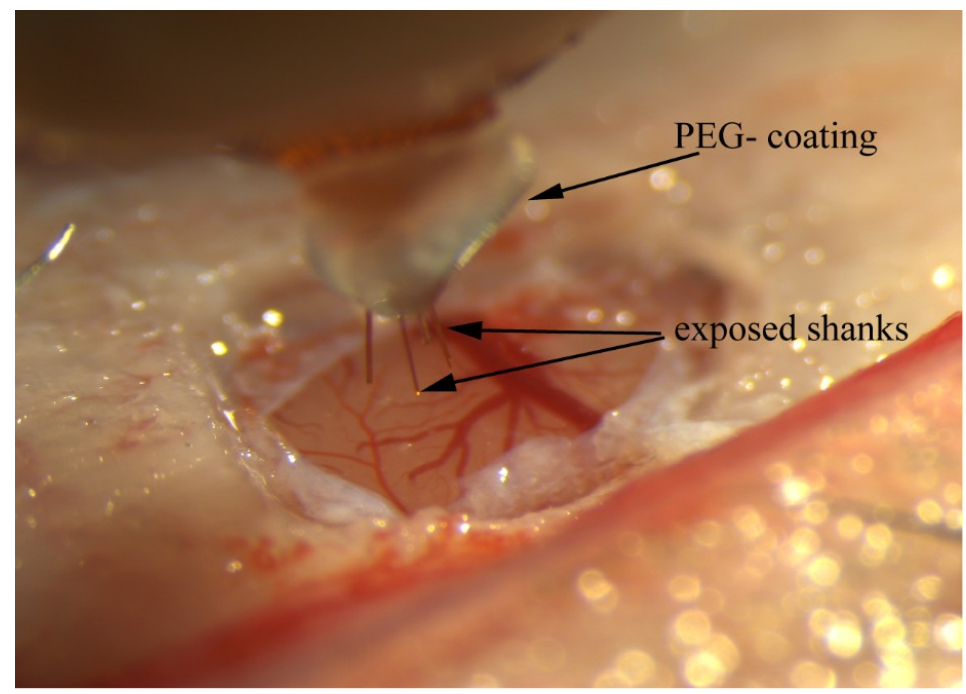

Figure 3. Insertion of a PEG-stabilized a-SiC MEA into rat motor cortex. The PEG temporarily provides mechanical support to the $4 \mu \mathrm{m}$ thick a-SiC shanks prior to insertion. An insertion rate of $50 \mu \mathrm{m} / \mathrm{s}$ ensures that the PEG completely dissolves as the array is advanced into the brain.

\subsubsection{Bundled Shanks}

Another successful approach introduced by Guitchounts et al. when working with carbon fiber ultramicroelectrodes was to draw the fibers into a bundle allowing the individual fibers to provide mechanical support to each other during array insertion [4]. This approach also increases the overall cross-sectional area of the bundled fibers and increases the buckling threshold for insertion. Since the fibers on the bundled array are held together by weak Van der Waals forces, they separate upon insertion and spread out into the brain following the path of least resistance defined by the mechanical heterogeneity of the brain [4]. The $4 \mu \mathrm{m}$ thick a-SiC arrays were successfully inserted using this approach, however unlike carbon fibers, we observed that the shanks of the a-SiC MEA twisted together or intertwined when drawn out of water. The tangled shanks prevented the individual shanks from separating and splaying when implanted. Further work is needed to find an appropriate surface treatment that would aid shank separation. Figure 4a shows a bundled a-SiC array formed when the shanks are drawn out of water. Figure $4 \mathrm{~b}$ shows the tip geometry of the bundle and Figure $4 \mathrm{c}$ shows a bundled 8-channel a-SiC array prior to rat cortical implantation.

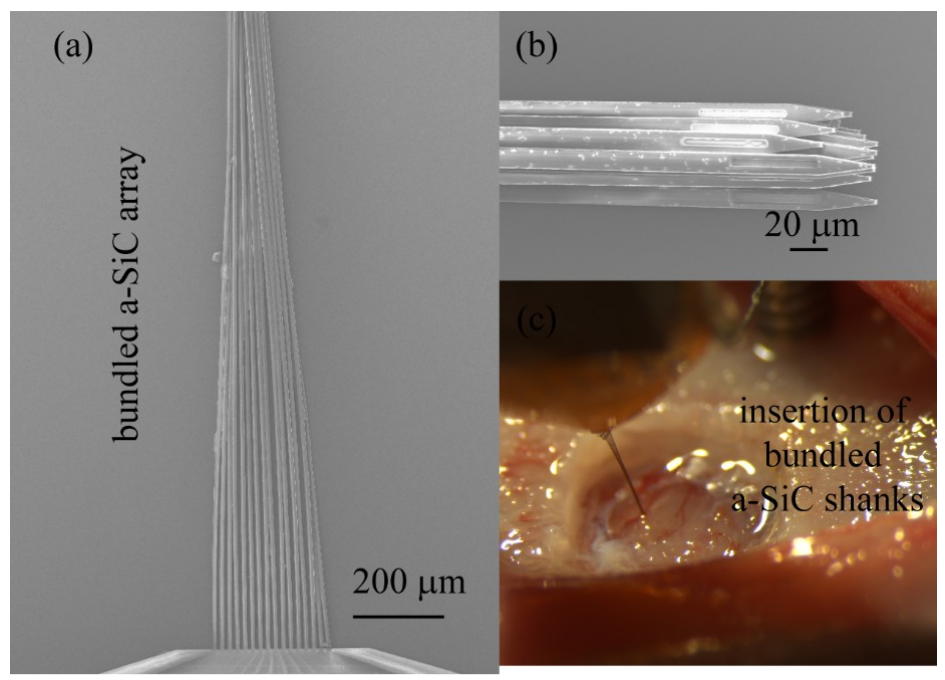

Figure 4. Bundles of 16-channel a-SiC MEA when drawn out of water (a) showing tip geometry (b). Insertion of a bundled 8-channel a-SiC array into rat cortex (c). 


\subsubsection{Reduction of Effective Shank Length}

Another factor that influences the critical buckling load is the effective length of the shanks. The effective length of a beam or a shank corresponds to the distance between the points of inflection in the buckled mode. The buckling threshold increases with decreasing effective length of the shank. Patel et al. [5], while working with carbon fibers, developed silicon support structures that enabled the insertion of $0.5 \mathrm{~mm}$ long carbon fibers to deeper structures within rat brain. For the carbon fibers, this was the minimum length that could be inserted into the brain without buckling [5]. The advantage of the a-SiC technology over the carbon fiber approach is that structures that will reduce the effective length of the shanks can be designed as part of the MEA geometry. The a-SiC thin film technology allows in situ designs in the a-SiC without the need for additional support structures and micro-assembly. As a result, shorter ultrathin a-SiC array shanks can be developed for insertion into deeper structures within the brain.

We designed and developed webbed a-SiC arrays as shown in Figure $5 b$ with an effective shank length below $1 \mathrm{~mm}$ for an overall insertion depth of $2 \mathrm{~mm}$ (including the hinged part). The individual shanks are fused in pairs by a-SiC film interconnects as the shanks approach the base of the MEA $5 \mathrm{~d}$ while maintaining the ultrathin geometries at the distal end 5a. Electrode sites are located at the distal end 5c. Amorphous SiC MEAs with ultrathin shank geometries ( $4 \mu \mathrm{m}$ thick $\times 10 \mu \mathrm{m}$ wide) have been successfully implanted when the shanks are webbed. This a-SiC lateral interconnect strategy increases the width of the shank towards the base and may induce lateral stresses in tissue and potentially induce host immune response. We are yet to evaluate the chronic response to these arrays. Since the electrode sites are located on shanks that maintain the critical dimension of $10 \mu \mathrm{m}$ or less, it is expected that the host immune response, at least around the electrode sites, will be minimized.

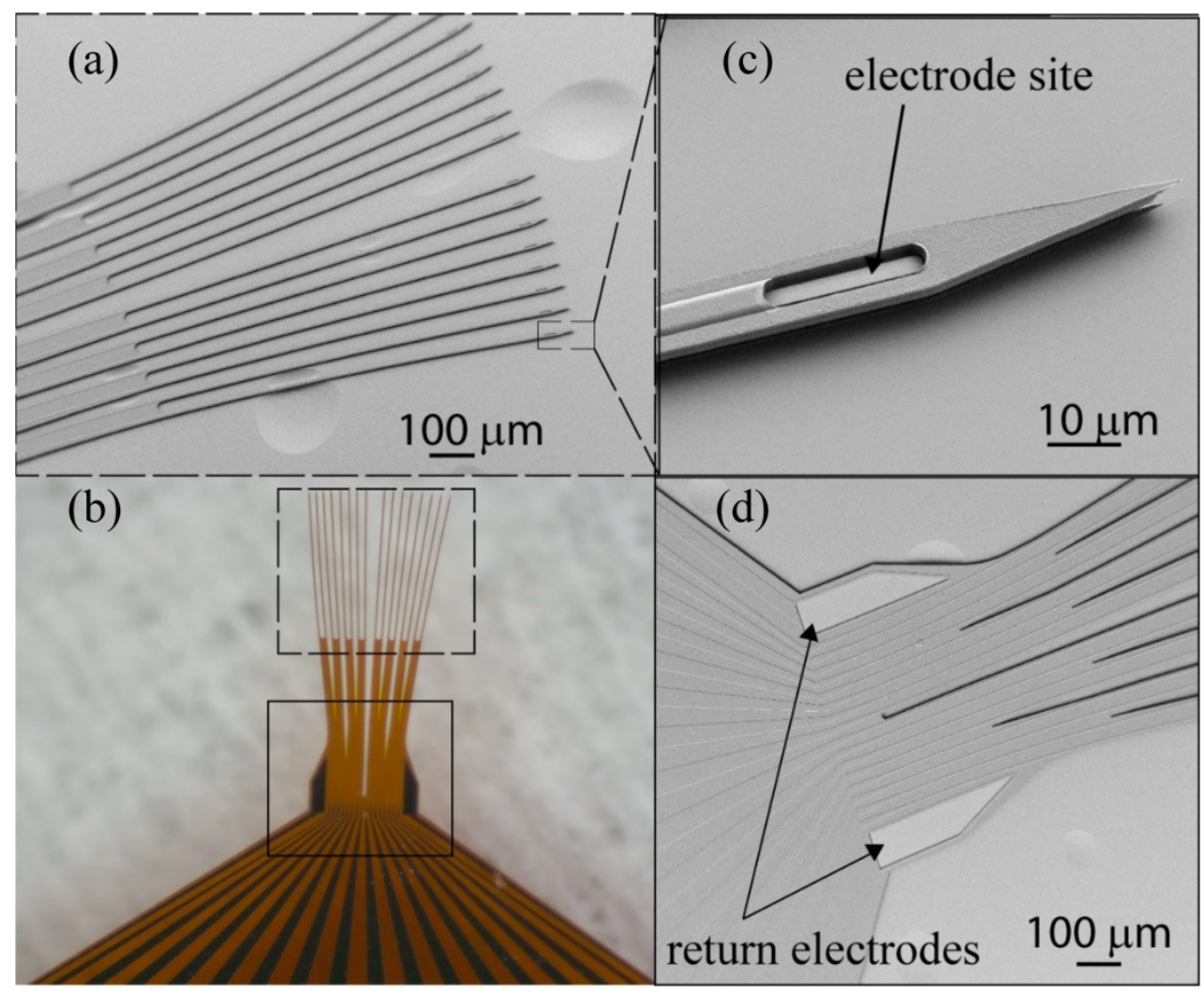

Figure 5. Webbed a-SiC MEA with an effective shank length of $1 \mathrm{~mm}$ and a monopolar stimulation current return electrode as part of the MEA structure. 


\subsubsection{Insertion of Individual Shanks}

A trade-off between flexibility and stiffness is required when developing compliant microelectrode arrays for cortical application [32]. Insertion of ultrathin flexible microelectrodes into neural tissue usually fails during implantation. The flexural rigidity (a product of the Young's modulus of the material and moments of inertia of the cross-section) of the shank is related to the critical buckling load by Equation (1) where $P_{c r}$ is the critical buckling load, $E$ is the Young's modulus, $I$ is the moment of inertia of cross-section, $l$ is the length, and $K$ is the column effective length factor (one fixed end, one pinned end $=0.7$ ). A Young's modulus of $300 \mathrm{GPa}$ was used for numerical calculations and simulation purposes. The Young's modulus of a-SiC films depends on deposition conditions and values between 150 and $321 \mathrm{GPa}$ have been reported in the literature [47-49].

$$
P_{c r}=\frac{\pi^{2} E I}{(K l)^{2}}
$$

The critical buckling load is the maximum axial load a shank can experience that will not cause lateral deflections. For a microelectrode shank to successfully penetrate the pia mater of a rat brain it is generally expected that its critical buckling load to be larger than tissue insertion force estimated to be approximately 0.5 to $2 \mathrm{mN}$ [50-54]. Since the moment of inertia of the cross-section, which influences critical buckling load, depends greatly on the thickness of the shank, COMSOL Multiphysics v. 5.2 (COMSOL AB, Stockholm, Sweden) finite element modeling was used to predict the critical buckling load of a $2 \mathrm{~mm}$ long shank when the a-SiC thickness is increased from $4 \mu \mathrm{m}$ to $6 \mu \mathrm{m}$.

Force values during a buckling test with a single shank dummy a-SiC probe with a $6 \mu \mathrm{m}$ thick and $7 \mu \mathrm{m}$ wide cross-section are shown in Figure 6a. The probe was lowered against a glass surface at a speed of $50 \mu \mathrm{m} / \mathrm{s}$. No sliding of the probe tip on the glass surface was observed. The lowering was paused when buckling was observed visually, as shown by the plateau at $0.69 \mathrm{mN}$ in Figure $6 \mathrm{a}$. Since the visually observed buckling occurs well-beyond the first deflection of the probe, the $0.69 \mathrm{mN}$ overestimates the buckling force that would be calculated from Equation (1), which is $\sim 0.2 \mathrm{mN}$ for the probe in Figure 6. The recorded buckling force of $0.69 \mathrm{mN}$ should also be adjusted for the nonzero compressive force on the tip when the load cell is tared, which is approximately $0.15 \mathrm{mN}$. The combined total force of $0.84 \mathrm{mN}$ is notably larger than the COMSOL modeling prediction of $0.17 \mathrm{mN}$, which is likely due to the uncertainty in the visual assessment of buckling onset and changing boundary conditions as the probe inserts into the brain. The visually observed deflection profile (Figure 6b) was generally in agreement with predictions from the modeling (Figure 6c). Penetration forces are highly dependent on the tip geometry of the implanted device, with larger devices generally exhibiting greater implantation forces. Sridharan et al. [55] measured penetration forces greater than $1 \mathrm{mN}$ using nanocomposite-based devices and observed significant dimpling upon implantation. Welkenhuysen et al. [56] demonstrated penetration forces greater than $0.6 \mathrm{mN}$ using silicon devices, again with significant dimpling.

A preliminary investigation of the forces involved in inserting a single a-SiC shank into rat cortex was conducted. The force-time curve during implantation of a single shank with a $6 \times 7 \mu \mathrm{m}^{2}$ cross-section at $50 \mu \mathrm{m} / \mathrm{s}$ is shown in Figure 7. From the curve, the point of penetration of the probe corresponds to an insertion force of $0.35 \mathrm{mN}$. Dimpling of the cortex was not evident. The maximum length of a $6 \times 7 \mu \mathrm{m}$ probe that can be inserted into brain without buckling is $1.4 \mathrm{~mm}$ based on Equation (1), using an insertion force of $0.35 \mathrm{mN}$, an a-SiC modulus of $300 \mathrm{GPa}$, and $K=0.7$, corresponding to boundary conditions at which the probe is pinned at the probe-brain interface and fixed at the proximal end. The calculated length likely underestimates that actual length that can be inserted without buckling. As the sharp tips of the probe penetrate the brain, the boundary condition at the probe-brain interface changes to a less challenging fixed condition and the effective length of the shank also decreases slightly. Forces due to brain micromotion (inset) after the probe was implanted to the full $2 \mathrm{~mm}$ depth show that the indwelling shank experience an extremely low 
tissue force which relaxed at a rate of $\sim 2.2 \mu \mathrm{N} / \mathrm{s}$. We have successfully implanted a single shank and multiple colinear shanks with thickness of $6 \mu \mathrm{m}$ into a $0.6 \%$ agarose gel phantom and into rat brain at an insertion rate of $50 \mu \mathrm{m} / \mathrm{s}$. To prevent the a-SiC arrays from forming bundles, a minimum intershank distance of $100 \mu \mathrm{m}$ was found necessary for the 7-10 $\mu \mathrm{m}$ wide shanks investigated. The data in Figure 7 represent the results of a single measurement only and additional studies are required to more fully quantify the forces involved in insertion of these devices into cortex, particularly with respect to the effects of tip geometry, shank cross-sectional dimensions, and shank length.

(a)

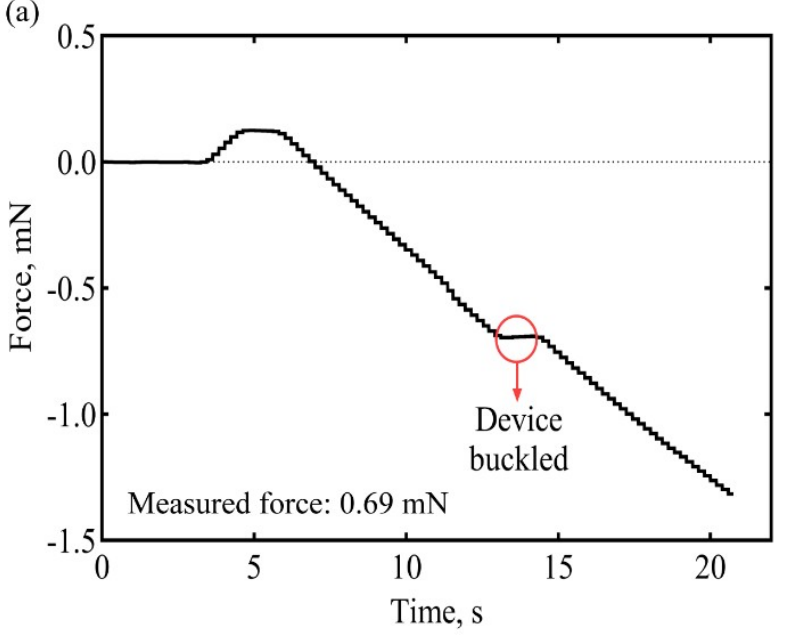

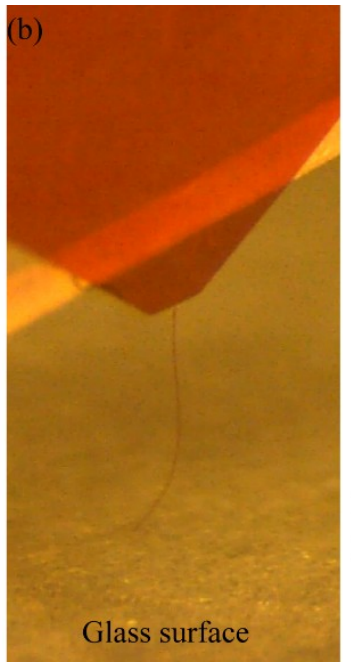

(c)

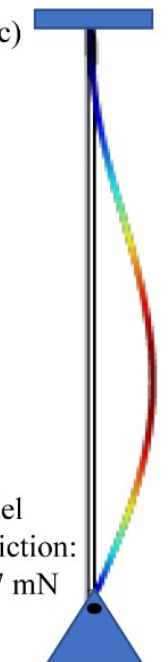

Figure 6. Buckling test. Force measured when a single shank a-SiC probe is lowered against a glass surface (a). An image of the buckled state of a $2 \mathrm{~mm}$ long shank (b) and a COMSOL prediction of the buckled state (c).

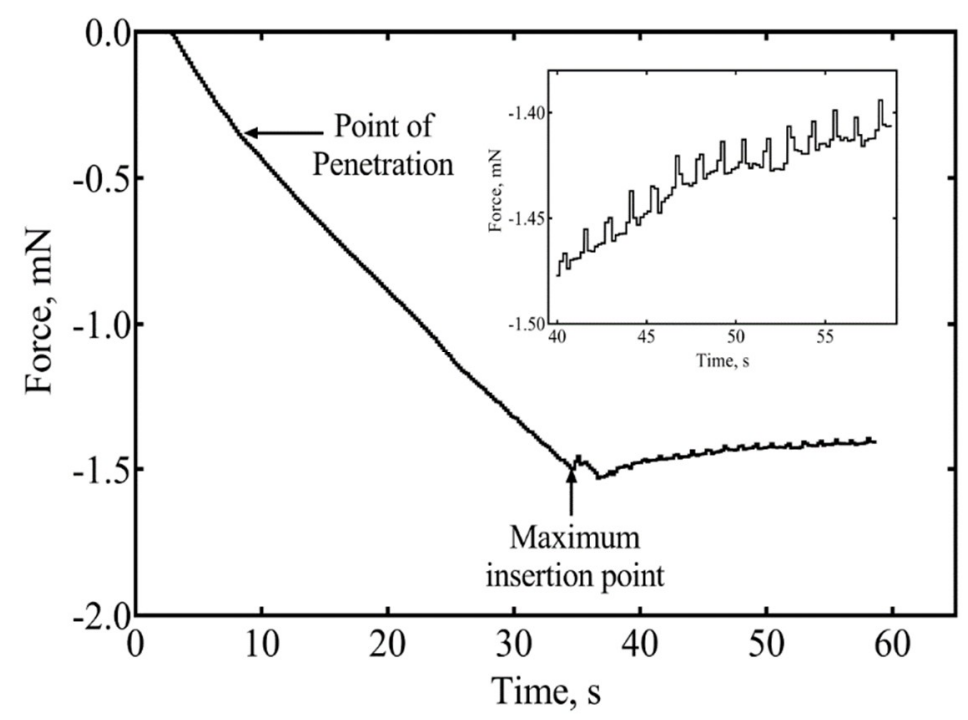

Figure 7. A representative example of the insertion force recorded during the insertion of a $6 \mu \mathrm{m} \times 7 \mu \mathrm{m}$ a-SiC shank into rat cortex. An insertion force of $0.35 \mathrm{mN}$ was recorded at the point of insertion. Inset shows forces experienced by the indwelling shank at $2 \mathrm{~mm}$ insertion depth.

\subsection{Neural Recording}

To determine whether $6 \mu \mathrm{m}$ a-SiC and SIROF MEAs could be used for in vivo single-unit extracellular recordings, we performed 10-min electrophysiological recordings immediately following implantation. Figure 8a shows three representative filtered continuous recordings from a single a-SiC array. Extracellular spikes were well-resolved and sorted based on characteristic waveform 
shape and 2D PC-space clustering into single units (Figure 8b). We observed distinguishable single units on between 25 and $75 \%$ of electrode sites, with the total number of units ranging from 4 to 16. These units had mean peak-to-peak amplitudes ranging from 118.5 to $287.7 \mu \mathrm{V}$, with a mean amplitude of $179.4 \pm 18.4 \mu \mathrm{V}$ and SNR of $24.1 \pm 2.2$. Table 1 contains RMS noise, mean amplitude, and SNR values for all three implanted arrays as well as cumulative means. These data suggest that $6 \mu \mathrm{m}$ a-SiC MEAs are stiff enough to penetrate the cortex without compromising their mechanical/electrical stability and their ability to record single-unit activity.

(a)
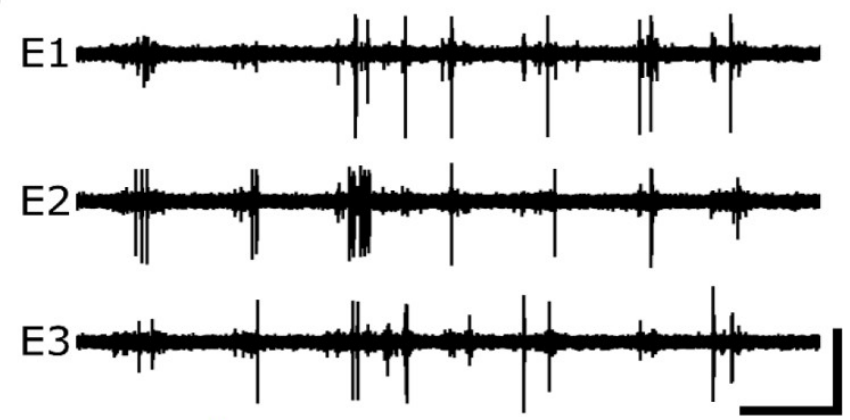

(b)

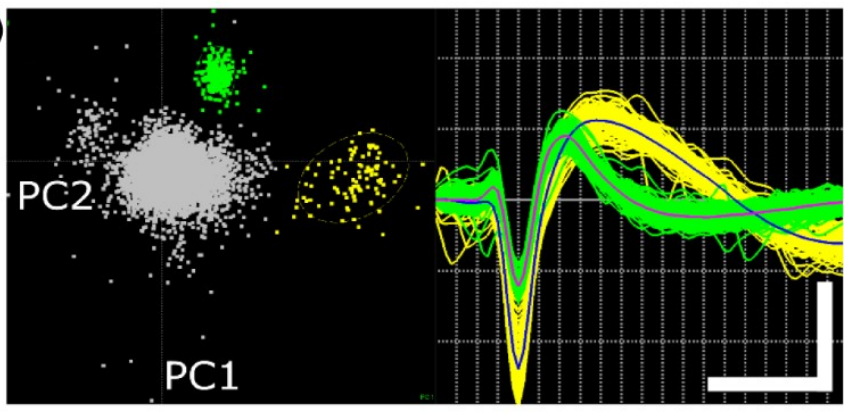

Figure 8. Acute extracellular action potentials recorded using $6 \mu \mathrm{m}$ a-SiC MEAs. (a) Filtered continuous data traces from three representative electrodes on Array 1. Vertical and horizontal scale bar represents $125 \mu \mathrm{V}$ and $1.75 \mathrm{~s}$, respectively. (b) Left-Representative 2D principal component space indicating clear separation from the noise (central gray cluster). Right-Associated single units, indicating characteristic extracellular waveform shape. Vertical and horizontal scale bar represents $175 \mu \mathrm{V}$ and $0.6 \mathrm{~ms}$, respectively.

Table 1. Active electrode yield (AEY) percentage, total number of units, mean peak-to-peak amplitude, RMS noise, and SNR per array, and cumulative values across all arrays.

\begin{tabular}{cccccc}
\hline Array \# & AEY (\%) & \# of Units & $\begin{array}{c}\text { Mean Vpp } \\
(\boldsymbol{\mu} \mathbf{V})\end{array}$ & $\begin{array}{c}\text { RMS Noise } \\
(\boldsymbol{\mu} \mathbf{V})\end{array}$ & SNR \\
\hline Array 1 & 75 & 16 & $179.0 \pm 19.8$ & $10.2 \pm 1.8$ & $25.6 \pm 2.9$ \\
Array 2 & 25 & 4 & $287.7 \pm 64.4$ & $8.8 \pm 0.2$ & $30.8 \pm 6.8$ \\
Array 3 & 31.3 & 7 & $118.5 \pm 12.2$ & $7.8 \pm 0.4$ & $16.7 \pm 1.7$ \\
Cumulative & $43.75 \%$ & 27 & $179.4 \pm 18.4$ & $8.9 \pm 0.6$ & $24.1 \pm 2.2$ \\
\hline
\end{tabular}

\section{Conclusions}

The a-SiC platform allows a wide design space to create next generation ultrathin neural interfaces. To reduce overall impedance associated with small electrodes of small geometric surface area, electrode sites could also be coated with common low impedance coating materials, such as TiN or SIROF which decrease the impedance by 2 orders of magnitude over a range of frequencies [35]. For MEAs developed with an overall a-SiC thickness of $4 \mu \mathrm{m}$, we have described various techniques which increase the critical buckling force of the individual shanks and enable penetration of the shanks without buckling. These methods include the addition of a temporary stiffening structure, bundling the individual 
shanks, or through in situ designs which reduced the effective length of the shanks while allowing for targeted depth penetration. With just the addition of a minimal amount of a-SiC material to a thickness of $6 \mu \mathrm{m}$, individual single shanks or colinear $2 \mathrm{~mm}$ long a-SiC fibers were successfully implanted into rat cortex without buckling. We have also demonstrated the ability to record neural signals using $6 \mu \mathrm{m}$ thick a-SiC MEAs acutely in rat motor cortex. Our results also indicated that SIROF-coated sites showed high amplitude and high SNR of the recorded neural signals.

Author Contributions: Conceptualization, F.D., J.J.P., and S.F.C.; Funding acquisition, T.J.G. and S.F.C.; Investigation, F.D., Y.C., and A.J.-I.; Methodology, F.D., C.L.F., A.S., S.A., and B.B.; Supervision, J.J.P. and S.F.C.; Writing—original draft, F.D. and C.L.F.; Writing—review \& editing, A.S., Y.C., S.A., A.J.-I., B.B., T.J.G., J.J.P., and S.F.C.

Funding: This research was funded by the National Institute of Health under grant number U01NS090454.

Acknowledgments: The University of Texas at Dallas Natural Sciences and Engineering Research Laboratory cleanroom staffers Gordon Pollock and Ronald Scott Riekena are acknowledged for their support in the maintenance of the PECVD tool.

Conflicts of Interest: The authors declare no conflicts of interest. The funders had no role in the design of the study; in the collection, analyses, or interpretation of data; in the writing of the manuscript, and in the decision to publish the results.

\section{References}

1. Jun, J.J.; Steinmetz, N.A.; Siegle, J.H.; Denman, D.J.; Bauza, M.; Barbarits, B.; Lee, A.K.; Anastassiou, C.A.; Andrei, A.; Aydın, Ç.; et al. Fully integrated silicon probes for high-density recording of neural activity. Nature 2017, 551, 232-236. [CrossRef] [PubMed]

2. Freire, M.A.M.; Morya, E.; Faber, J.; Santos, J.R.; Guimaraes, J.S.; Lemos, N.A.M.; Sameshima, K.; Pereira, A.; Ribeiro, S.; Nicolelis, M.A.L. Comprehensive Analysis of Tissue Preservation and Recording Quality from Chronic Multielectrode Implants. PLoS ONE 2011, 6, e27554. [CrossRef] [PubMed]

3. McCreery, D.B.; Yuen, T.G.H.; Agnew, W.F.; Bullara, L.A. Stimulation with chronically implanted microelectrodes in the cochlear nucleus of the cat: Histologic and physiologic effects. Hear. Res. 1992, 62, 42-56. [CrossRef]

4. Guitchounts, G.; Markowitz, J.E.; Liberti, W.A.; Gardner, T.J. A carbon-fiber electrode array for long-term neural recording. J. Neural Eng. 2013, 10, 046016. [CrossRef] [PubMed]

5. Patel, P.R.; Na, K.; Zhang, H.; Kozai, T.D.Y.; Kotov, N.A.; Yoon, E.; Chestek, C.A. Insertion of linear $8.4 \mu \mathrm{m}$ diameter 16 channel carbon fiber electrode arrays for single unit recordings. J. Neural Eng. 2015, 12, 046009. [CrossRef] [PubMed]

6. Deku, F.; Joshi-Imre, A.; Mertiri, A.; Gardner, T.J.; Cogan, S.F. Electrodeposited Iridium Oxide on Carbon Fiber Ultramicroelectrodes for Neural Recording and Stimulation. J. Electrochem. Soc. 2018, 165, D375-D380. [CrossRef]

7. Gillis, W.F.; Lissandrello, C.A.; Shen, J.; Pearre, B.W.; Mertiri, A.; Deku, F.; Cogan, S.; Holinski, B.J.; Chew, D.J.; White, A.E.; et al. Carbon fiber on polyimide ultra-microelectrodes. J. Neural Eng. 2018, 15, 016010. [CrossRef] [PubMed]

8. Seto, J.Y.W. The electrical properties of polycrystalline silicon films. J. Appl. Phys. 1975, 46, 5247-5254. [CrossRef]

9. Batey, J.; Tierney, E. Low-temperature deposition of high-quality silicon dioxide by plasma-enhanced chemical vapor deposition. J. Appl. Phys. 1986, 60. [CrossRef]

10. Yang, T.-C.; Saraswat, K.C. Effect of physical stress on the degradation of thin SiO/sub 2/ films under electrical stress. IEEE Trans. Electron. Devices 2000, 47, 746-755. [CrossRef]

11. Sheikholeslami, A.; Parhami, F.; Puchner, H.; Selberherr, S. Planarization of Silicon Dioxide and Silicon Nitride Passivation Layers. J. Phys. Conf. Ser. 2007, 61, 1051-1055. [CrossRef]

12. Hetke, J.F.; Lund, J.L.; Najafi, K.; Wise, K.D.; Anderson, D.J. Silicon Ribbon Cables for Chronically Implantable Microelectrode Arrays. IEEE Trans. Biomed. Eng. 1994, 41, 314-321. [CrossRef] [PubMed]

13. Barrese, J.C.; Aceros, J.; Donoghue, J.P. Scanning electron microscopy of chronically implanted intracortical microelectrode arrays in non-human primates. J. Neural Eng. 2016, 13, 026003. [CrossRef] [PubMed] 
14. Barrese, J.C.; Rao, N.; Paroo, K.; Triebwasser, C.; Vargas-Irwin, C.; Franquemont, L.; Donoghue, J.P. Failure mode analysis of silicon-based intracortical microelectrode arrays in non-human primates. J. Neural Eng. 2013, 10, 066014. [CrossRef] [PubMed]

15. Kane, S.R.; Cogan, S.F.; Ehrlich, J.; Plante, T.D.; McCreery, D.B.; Troyk, P.R. Electrical performance of penetrating microelectrodes chronically implanted in cat cortex. IEEE Trans. Biomed. Eng. 2013, 60, 2153-2160. [CrossRef] [PubMed]

16. Hassler, C.; Boretius, T.; Stieglitz, T. Polymers for neural implants. J. Polym. Sci. Part B Polym. Phys. 2011, 49, 18-33. [CrossRef]

17. Metz, S.; Bertsch, A.; Bertrand, D.; Renaud, P. Flexible polyimide probes with microelectrodes and embedded microfluidic channels for simultaneous drug delivery and multi-channel monitoring of bioelectric activity. Biosens. Bioelectron. 2004, 19, 1309-1318. [CrossRef] [PubMed]

18. Rousche, P.J.; Pellinen, D.S.; Pivin, D.P.; Williams, J.C.; Vetter, R.J.; Kipke, D.R. Flexible polyimide-based intracortical electrode arrays with bioactive capability. IEEE Trans. Biomed. Eng. 2001, 48, 361-371. [CrossRef] [PubMed]

19. Kim, B.J.; Kuo, J.T.W.; Hara, S.A.; Lee, C.D.; Yu, L.; Gutierrez, C.A.; Hoang, T.Q.; Pikov, V.; Meng, E. 3D Parylene sheath neural probe for chronic recordings. J. Neural Eng. 2013, 10, 045002. [CrossRef] [PubMed]

20. Takeuchi, S.; Ziegler, D.; Yoshida, Y.; Mabuchi, K.; Suzuki, T. Parylene flexible neural probes integrated with microfluidic channels. Lab Chip 2005, 5, 519. [CrossRef] [PubMed]

21. Altuna, A.; Bellistri, E.; Cid, E.; Aivar, P.; Gal, B.; Berganzo, J.; Gabriel, G.; Guimerà, A.; Villa, R.; Fernández, L.J.; et al. SU-8 based microprobes for simultaneous neural depth recording and drug delivery in the brain. Lab Chip 2013, 13, 1422. [CrossRef] [PubMed]

22. Liang, G.; DeWeerth, S.P. PDMS-based conformable microelectrode arrays with selectable novel 3-D microelectrode geometries for surface stimulation and recording. Conf. Proc. IEEE Eng. Med. Biol. Soc. 2009, 2009, 1623-1626. [CrossRef]

23. Ware, T.; Simon, D.; Rennaker, R.L.; Voit, W. Smart Polymers for Neural Interfaces. Polym. Rev. 2013, 53, 108-129. [CrossRef]

24. Simon, D.M.; Charkhkar, H.; St. John, C.; Rajendran, S.; Kang, T.; Reit, R.; Arreaga-Salas, D.; McHail, D.G.; Knaack, G.L.; Sloan, A.; et al. Design and demonstration of an intracortical probe technology with tunable modulus. J. Biomed. Mater. Res. Part A 2017, 105, 159-168. [CrossRef] [PubMed]

25. Wei, X.; Luan, L.; Zhao, Z.; Li, X.; Zhu, H.; Potnis, O.; Xie, C. Nanofabricated Ultraflexible Electrode Arrays for High-Density Intracortical Recording. Adv. Sci. 2018, 5, 1700625. [CrossRef] [PubMed]

26. Gopalakrishnaiah, S.K.; Joseph, K.; Hofmann, U.G. Microfluidic drive for flexible brain implants. Curr. Dir. Biomed. Eng. 2017, 3, 675-678. [CrossRef]

27. Kozai, T.D.Y.; Kipke, D.R. Insertion shuttle with carboxyl terminated self-assembled monolayer coatings for implanting flexible polymer neural probes in the brain. J. Neurosci. Methods 2009, 184, 199-205. [CrossRef] [PubMed]

28. Shoffstall, A.J.; Srinivasan, S.; Willis, M.; Stiller, A.M.; Ecker, M.; Voit, W.E.; Pancrazio, J.J.; Capadona, J.R. A Mosquito Inspired Strategy to Implant Microprobes into the Brain. Sci. Rep. 2018, 8, 122. [CrossRef] [PubMed]

29. Lo, M.; Wang, S.; Singh, S.; Damodaran, V.B.; Kaplan, H.M.; Kohn, J.; Shreiber, D.I.; Zahn, J.D. Coating flexible probes with an ultra fast degrading polymer to aid in tissue insertion. Biomed. Microdevices 2015, 17, 34. [CrossRef] [PubMed]

30. Lewitus, D.; Smith, K.L.; Shain, W.; Kohn, J. Ultrafast resorbing polymers for use as carriers for cortical neural probes. Acta Biomater. 2011, 7, 2483-2491. [CrossRef] [PubMed]

31. Lind, G.; Linsmeier, C.E.; Thelin, J.; Schouenborg, J. Gelatine-embedded electrodes-A novel biocompatible vehicle allowing implantation of highly flexible microelectrodes. J. Neural Eng. 2010, 7, 046005. [CrossRef] [PubMed]

32. Lecomte, A.; Descamps, E.; Bergaud, C. A review on mechanical considerations for chronically-implanted neural probes. J. Neural Eng. 2018, 15, 031001. [CrossRef] [PubMed]

33. Sohal, H.S.; Clowry, G.J.; Jackson, A.; O’Neill, A.; Baker, S.N. Mechanical Flexibility Reduces the Foreign Body Response to Long-Term Implanted Microelectrodes in Rabbit Cortex. PLoS ONE 2016, 11, e0165606. [CrossRef] [PubMed] 
34. Seymour, J.P.; Kipke, D.R. Neural probe design for reduced tissue encapsulation in CNS. Biomaterials 2007, 28, 3594-3607. [CrossRef] [PubMed]

35. Deku, F.; Cohen, Y.; Joshi-Imre, A.; Kanneganti, A.; Gardner, T.J.; Cogan, S.F. Amorphous silicon carbide ultramicroelectrode arrays for neural stimulation and recording. J. Neural Eng. 2018, 15, 016007. [CrossRef] [PubMed]

36. Azevedo, R.G.; Zhang, J.; Jones, D.G.; Myers, D.R.; Jog, A.V.; Jamshidi, B.; Wijesundara, M.B.J.; Maboudian, R.; Pisano, A.P. Silicon carbide coated MEMS strain sensor for harsh environment applications. Proceeding of the 2007 IEEE 20th International Conference on Micro Electro Mechanical Systems (MEMS), Hyogo, Japan, 21-25 January 2007; IEEE: Piscataway, NJ, USA, 2007; pp. 643-646.

37. Cogan, S.F.; Edell, D.J.; Guzelian, A.A.; Liu, Y.P.; Edell, R. Plasma-enhanced chemical vapor deposited silicon carbide as an implantable dielectric coating. J. Biomed. Mater. Res. A 2003, 67, 856-867. [CrossRef] [PubMed]

38. Knaack, G.L.; Charkhkar, H.; Cogan, S.F.; Pancrazio, J.J. Amorphous Silicon Carbide for Neural Interface Applications. Silicon Carbide Biotechnol. 2016, 249-260. [CrossRef]

39. Knaack, G.L.; McHail, D.G.; Borda, G.; Koo, B.S.; Peixoto, N.; Cogan, S.F.; Dumas, T.C.; Pancrazio, J.J. In vivo Characterization of Amorphous Silicon Carbide as a Biomaterial for Chronic Neural Interfaces. Front. Neurosci. 2016, 10, 301. [CrossRef] [PubMed]

40. Iliescu, C.; Chen, B.; Poenar, D.P.; Lee, Y.Y. PECVD amorphous silicon carbide membranes for cell culturing. Sensors Actuators, B Chem. 2008, 129, 404-411. [CrossRef]

41. Frewin, C.L.; Locke, C.; Saddow, S.E.; Weeber, E.J. Single-crystal cubic silicon carbide: An in vivo biocompatible semiconductor for brain machine interface devices. Proceeding of the 2011 Annual International Conference of the IEEE Engineering in Medicine and Biology Society, Boston, MA, USA, 30 August-3 September 2011; IEEE: Piscataway, NJ, USA, 2011; pp. 2957-2960.

42. Oliveros, A.; Guiseppi-Elie, A.; Saddow, S.E. Silicon carbide: a versatile material for biosensor applications. Biomed. Microdevices 2013, 15, 353-368. [CrossRef] [PubMed]

43. Diaz-Botia, C.A.; Luna, L.E.; Chamanzar, M.; Carraro, C.; Sabes, P.N.; Maboudian, R.; Maharbiz, M.M. Fabrication of all-silicon carbide neural interfaces. Proceeding of the 2017 8th International IEEE/EMBS Conference on Neural Engineering (NER), Shanghai, China, 25-28 May 2017; IEEE: Piscataway, NJ, USA, 2017; pp. 170-173.

44. Bernardin, E.; Frewin, C.; Everly, R.; Ul Hassan, J.; Saddow, S.; Bernardin, E.K.; Frewin, C.L.; Everly, R.; U1 Hassan, J.; Saddow, S.E. Demonstration of a Robust All-Silicon-Carbide Intracortical Neural Interface. Micromachines 2018, 9, 412. [CrossRef]

45. Frewin, C.L.; Bernardin, E.E.; Deku, F.; Everly, R.; Hassan, J.; Pancrazio, J.J.; Saddow, S.E. Silicon Carbide as a Robust Neural Interface. ECS Trans. 2016, 75, 39-45. [CrossRef]

46. Pancrazio, J.J.; Deku, F.; Ghazavi, A.; Stiller, A.M.; Rihani, R.; Frewin, C.L.; Varner, V.D.; Gardner, T.J.; Cogan, S.F. Thinking Small: Progress on Microscale Neurostimulation Technology. Neuromodulation Technol. Neural Interface 2017, 20, 745-752. [CrossRef] [PubMed]

47. El Khakani, M.A.; Chaker, M.; Jean, A.; Boily, S.; Kieffer, J.C.; O’Hern, M.E.; Ravet, M.F.; Rousseaux, F. Hardness and Young's modulus of amorphous a-SiC thin films determined by nanoindentation and bulge tests. J. Mater. Res. 1994, 9, 96-103. [CrossRef]

48. Cros, B.; Gat, E.; Saurel, J. Characterization of the elastic properties of amorphous silicon carbide thin films by acoustic microscopy. J. Non. Cryst. Solids 1997, 209, 273-282. [CrossRef]

49. Xue, K.; Niu, L.-S.; Shi, H.-J. Mechanical Properties of Amorphous Silicon Carbide. Silicon Carbide IntechOpen 2011. [CrossRef]

50. Jensen, W.; Yoshida, K.; Hofmann, U.G. In-vivo implant mechanics of flexible, silicon-based ACREO microelectrode arrays in rat cerebral cortex. IEEE Trans. Biomed. Eng. 2006, 53, 934-940. [CrossRef] [PubMed]

51. Wester, B.A.; Lee, R.H.; LaPlaca, M.C. Development and characterization of in vivo flexible electrodes compatible with large tissue displacements. J. Neural Eng. 2009, 6, 024002. [CrossRef] [PubMed]

52. Howard, M.A.; Abkes, B.A.; Ollendieck, M.C.; Noh, M.D.; Ritter, C.; Gillies, G.T. Measurement of the force required to move a neurosurgical probe through in vivo human brain tissue. IEEE Trans. Biomed. Eng. 1999, 46, 891-894. [CrossRef] [PubMed] 
53. Molloy, J.A.; Ritter, R.C.; Grady, M.S.; Howard, M.A.; Quate, E.G.; Gillies, G.T. Experimental determination of the force required for insertion of a thermoseed into deep brain tissues. Ann. Biomed. Eng. 1990, 18, $299-313$. [CrossRef] [PubMed]

54. Tian, C.X.; He, J. Monitoring Insertion Force and Electrode Impedance during Implantation of Microwire Electrodes. Proceeding of the 2005 IEEE Engineering in Medicine and Biology 27th Annual Conference, Shanghai, China, 17-18 January 2006; IEEE: Piscataway, NJ, USA, 2006; pp. 7333-7336.

55. Sridharan, A.; Nguyen, J.K.; Capadona, J.R.; Muthuswamy, J. Compliant intracortical implants reduce strains and strain rates in brain tissue in vivo. J. Neural Eng. 2015, 12, 036002. [CrossRef] [PubMed]

56. Welkenhuysen, M.; Andrei, A.; Ameye, L.; Eberle, W.; Nuttin, B. Effect of Insertion Speed on Tissue Response and Insertion Mechanics of a Chronically Implanted Silicon-Based Neural Probe. IEEE Trans. Biomed. Eng. 2011, 58, 3250-3259. [CrossRef] [PubMed]

(C) 2018 by the authors. Licensee MDPI, Basel, Switzerland. This article is an open access article distributed under the terms and conditions of the Creative Commons Attribution (CC BY) license (http://creativecommons.org/licenses/by/4.0/). 